\title{
NGHIÊN CỨU GIẢI PHẪU MỎM YÊN TRƯớC TRÊN PHIM CHỤP CẮT LỚP VI TÍNH ĐA DÃY
}

\author{
Nguyễn Đức Nghĩa ${ }^{1}$, Nguyễn Lê Minh Tiến ${ }^{1}$, \\ Tạ Văn Lâm², Ngô Mạnh Hùng ${ }^{2}$
}

\section{TÓM TẮT}

Mục tiêu: mô tả kích thước và phân bố mức độ khí hóa của mỏm yên trước. Đối tượng và phương pháp nghiên cứu: nghiên cứu giải phẫu mỏm yên trước nhóm 60 bệnh nhân (30 nam và 30 nữ) trên phim chụp cắt lớp vi tính đa dãy. Kết quả nghiên cứu: chiều dài mỏm yên trước $(9,57 \pm 1,90 \mathrm{~mm})$; chiều rộng mỏm yên trước $(10,57 \pm 1,66 \mathrm{~mm})$. Có sự khác biệt có ý nghĩa thống kê về chiêu dài của mỏm yên trước bên trái so với bên phải ở nữ. $26,67 \%$ số bệnh nhân có khí hóa với các mức đọ khác nhau ở mỏm yên trước. Khí hóa loại I là dang khí hóa thường gặp nhẫ́t của mỏm yên trước. Kết luận: Nghiên cứu giải phẫu mỏm yên trước trên phim chụp cắt lớp vi tính đa dãy là phương pháp hữu hiệu, có tính cập nhật và tương thích với các nghiên cứu khác.

\section{SUMMARY}

\section{A STUDY OF THE ANTERIOR CLINOID PROCESS ANATOMY ON THE MULTIPLE SLIDE COMPUTED TOMOGRAPHY}

Objectives: Describe the diameter and pneumatization of the anterior clinoid process. Patients and methods: a study of the anterior clinoid process anatomy in the cohort of 60 patients on the thin-multiple slide computed tomography. Results: The length and width were $9.57 \pm 1.90$ and $10.57 \pm 1.66$, respectively. There was a significant difference between the length of the anterior clinoid process on the right and left sides in the women. Pneumatization of the anterior clinoid process was revealed in 26.67 percent of patients. Type I of pneumatization was the most common. Conclusion: Anatomic study of the anterior clinoid process on the multiple slide computed tomography with thin-slide was a valuable and updated method compatible with other studies

\section{I. ĐĂT VẤN ĐỀ}

Mỏm yên trước là phần lồi vào trong của cánh nhỏ xương bướm,được bao quanh bởi các cấu trúc thần kinh và mạch máu quan trọng như động mạch cảnh trong, thần kinh thị giác, xoang tĩnh mạch hang với các thành phần liên quan của nó. Phẫu thuật lấy bỏ mỏm yên trước là một

\footnotetext{
${ }^{1}$ Đai hoc Y Hà nọi

${ }^{2}$ Bềnh viên Viêt Đức

Chịu trách nhiệm chính: Ngô Mạnh Hùng

Email: ngomanhhung2000@gmail.com

Ngày nhận bài: 19.01.2021

Ngày phản biên khoa hoc: 15.3.2021

Ngày duyệt bài: 24.3.2021
}

trong các kỹ thuật quan trọng trong tiếp cận các tổn thương quanh mỏm yên trước, như phình động mạch cảnh trong đoạn mắt, u màng não mỏm yên-cánh nhỏ xương bướm, cũng như các tổn thương của xoang hang [1]. Do sự phức tạp này, đối với các phình động mạch quanh vùng mỏm yên trước thường được chỉ định điều trị bằng can thiệp mạch, tuy nhiên vai trò của phẫu thuật tới vùng này vẫn còn rất rộng rãi. Vì vậy, hiểu biết giải phẫu mỏm yên trước rất quan trọng trong việc áp dụng trong phẫu thuật. Hiện nay, chụp vi tính đa dãy có thể giúp dựng hình chi tiết cấu trúc giải phẫu của mỏm yển trước, khiến cho việc nghiên cứu giải phẫu cũng như các biến đổi giải phẫu của chúng trở nên khả thi hơn. Chúng tôi tiến hành nghiên cứu về giải phẫu mỏm yên trước trên phim chụp cắt lớp vi tính đa dãy nhằm mục đích: (1) mô tả các biến đôi giải phẫu của móm yên trước, và (2) đo đạc các kích thước của móm yên trước trên phim chụp cắt lớp vi tính đa dãy.

\section{II. ĐỐI TƯợNG VÀ PHƯƠNG PHÁP NGHIÊN CỨU}

Nghiên cứu giải phẫu mỏm yên trước dựa trên phim chụp cắt lớp vi tính đa dãy

\section{Tiêu chuẩn lựa chon}

- Bệnh nhân trên 18 tuổi

- Không có tiền sử phẫu thuật ảnh hưởng đến sự toàn vẹn của các cấu trúc giải phẫu vùng hố yển-mỏm yên (mổ nền sọ, mổ xoang hàm, hàm mặt...)

- Không có tiền sử viêm nhiễm vùng hàm mặt, các xoang cạnh mũi (xoang hàm, xoang bướm, xoang sàng)

- Không có bệnh lý liên quan và ảnh hưởng đến sự phát triển của các cấu trúc của xương (ví dụ như u xương sọ, phình động mạch não đoạn mắt, u màng não quanh vùng mỏm yên...)

- Không có tiền sử chấn thương sọ não gây võ nền sọ, dò dịch não tủy...

- Được chụp phim cắt lớp vi tính đa dãy sọ não, nền sọ

- Có đầy đủ các thông tin về nhân chủng học (tuổi, giới)

Tiêu chuẩn loại trừ

- Không có ít nhất một trong các tiêu chuẩn lựa chọn trên

- Vùng sọ mặt có dị vật khiến cho nhiễu hình ảnh khi chụp 
Phương pháp thu thập số liệu: Đo trực tiếp trên phần mềm PACS Infinity, máy CT (MSCT Optima CT540, GE) 120kV, 35mAs, độ dày của các lát cắt : $0,625 \mathrm{~mm}$ ở hình ảnh cửa sổ xương xóa nhu mô não.

Thời gian nghiên cứu: 6.2020 đến 3.2021

Phương pháp chọn mẫu: Lấy ngẫu nhiên ở 3 thời điểm, mỗi thời điểm gồm 10 bệnh nhân nữ, 10 bệh nhân nam đủ tiêu chuẩn lựa chon. Tổng số bệnh nhân trong nghiên cứu: 60 (30 nam và 30 nữ).

Các biến số nghiên cứu: tuổi, giới, khoảng cách xa nhất giữa hai mỏm yên trước, chiều dài và chiều rộng của mỏm yên, phân độ khí hóa của mỏm yên theo phân loại của Abuzayed [2] (bảng 1).

Bảng 1. Phân loại mức độ khí hóa theo Abuzayed

\begin{tabular}{|c|c|c|}
\hline Phân độ & Mô tả & $x^{2}+x^{2}$ \\
\hline 0 & $\begin{array}{l}\text { Không có bất kỳ } \\
\text { sự khí hóa nào }\end{array}$ & \\
\hline I & $\begin{array}{l}\text { Chưa xuất hiện } \\
\text { khí hóa mỏm yên } \\
\text { trước, có sự khí } \\
\text { hóa ớ optic strut }\end{array}$ & sF \\
\hline II & $\begin{array}{l}\text { IIa. Khí hóa } \leq \\
50 \% \text { mỏm yên } \\
\text { trước thông qua } \\
\text { Optic strut } \\
\text { IIb. Khí hóa > } \\
50 \% \text { mỏm yên } \\
\text { trước thông qua } \\
\text { Optic strut }\end{array}$ & $\begin{array}{l}\mathrm{a} \\
\mathrm{SF}\end{array}$ \\
\hline III & $\begin{array}{l}\text { Khí hóa mỏm yên } \\
\text { trước thông trực } \\
\text { tiếp với xoang } \\
\text { bướm (có hoặc } \\
\text { không sự khí hóa } \\
\text { optic strut) }\end{array}$ & a \\
\hline
\end{tabular}

\section{KẾT QUẢ NGHIÊN CỨU}

Nghiên cứu của chúng tôi dựa trên nhóm 60 bệnh nhân trưởng thành ( $\geq 18$ tuổi), với 30 nam và 30 nữ. Tuổi trung bình của nhóm nghiên cứu là: 45,53 $\pm 14,69$ dao động từ 18-75 tuổi. Khoảng cách xa nhất giữa 2 mỏm yên trước là 22,71 $\pm 2,04 \mathrm{~mm}$ (dao động từ 19,02$27,9 \mathrm{~mm})$, không có sự khác biệt giữa nam và nữ với $p=0.051$

Chiều rộng mỏm yên trước 10,57 $\pm 1,66$ mm, dao động từ 7,35-15,71 (mm)
Chiều dài mỏm yên trước $9,57 \pm 1,90 \mathrm{~mm}$, dao động từ 5,72-14,68 (mm)

Bảng 2. Kích thước chung của mỏm yên trước (MYT) phân bố theo giới

\begin{tabular}{|c|c|c|c|}
\hline & \multicolumn{2}{|c|}{ Kích thước $(\mathbf{m m})$} & \multirow{2}{*}{ P } \\
\cline { 2 - 3 } & $\mathbf{N a m}$ & $\mathbf{N u ̛ ̃}$ & \\
\hline Chiều rộng & 10,73 & 10,41 & \multirow{2}{*}{0,458} \\
mỏm yên trước & $\pm 1,91$ & $\pm 1,38$ & \\
\hline Chiều dài mỏm & 9,82 & 9,32 & \\
yên trước & $\pm 2,04$ & $\pm 1,76$ & 0,315 \\
\hline
\end{tabular}

Bảng 3. Liên quan kích thước chiều dài và chiều rộng của móm yên trước (MYT) bên Phải và bên Trái theo giới tính

\begin{tabular}{|c|c|c|c|}
\hline Giới & Biến số & Kích thước & $\mathrm{p}$ \\
\hline \multirow{2}{*}{ Nữ } & Chiều rộng MYT bên Phải & $10,56 \pm 1,63$ & \multirow{2}{*}{0,186} \\
\cline { 2 - 3 } & Chiều rộng MYT bên Trái & $10,27 \pm 1,25$ & 0,719 \\
\hline \multirow{2}{*}{ Nam } & Chiều rộng MYT bên Phải & $10,69 \pm 2,16$ & 0 \\
\hline
\end{tabular}


TAP CHÍ Y HỌC VIẸT NAM TẬP 501 - THÁNG 4 - SÓ 1 - 2021

\begin{tabular}{|c|c|c|c|}
\hline \multirow{2}{*}{ Nữ } & Chiều rộng MYT bên Trái & $10,78 \pm 1,87$ & \\
\cline { 2 - 3 } & Chiều dài MYT bên Phải & $9,30 \pm 1,87$ & \multirow{2}{*}{$\mathbf{0 , 0 0 4}$} \\
\cline { 2 - 3 } & Chiều dài MYT bên Trái & $9,61 \pm 1,79$ & \multirow{2}{*}{0,093} \\
\cline { 2 - 3 } \multirow{2}{*}{ Nam } & Chiều dài MYT bên Phải & $9,62 \pm 2,22$ & $10,02 \pm 2,04$ \\
\cline { 2 - 3 }
\end{tabular}

Bảng 4. Sự xuất hiện khí hóa mỏm yên trước trên phim chụp cắt lớp vi tính

\begin{tabular}{|c|c|c|c|c|c|c|}
\hline \multirow{2}{*}{\multicolumn{2}{|c|}{ Mức độ khí hóa mỏm yên trước }} & \multicolumn{2}{|c|}{$\operatorname{Nam}(n=30)$} & \multicolumn{2}{|c|}{ Nữ $(n=30)$} & \multirow{2}{*}{ P* } \\
\hline & & $\mathbf{n}$ & $\%$ & $\mathbf{n}$ & $\%$ & \\
\hline \multicolumn{2}{|c|}{ Không có $(n=44)$} & 20 & 66,7 & 24 & 80 & \multirow{5}{*}{0,443} \\
\hline \multirow[b]{3}{*}{ Có $(n=16)$} & Phải & 2 & 6,7 & 2 & 6,7 & \\
\hline & Trái & 3 & 10,0 & 3 & 10,0 & \\
\hline & Hai bên & 5 & 16,7 & 1 & 3,3 & \\
\hline \multicolumn{2}{|c|}{ Tống số } & 30 & 100.0 & 30 & 100.0 & \\
\hline
\end{tabular}

*p value được kiểm định bởi Chi-square test

Bảng 5. Phân bố mức độ khí hóa theo phân loại của Abuzayed

\begin{tabular}{|c|c|c|c|c|}
\hline & Type I & Type II & $\begin{array}{c}\text { Type } \\
\text { III }\end{array}$ & \multirow{2}{*}{ P* } \\
\cline { 2 - 3 } & \multicolumn{3}{|c|}{$\mathbf{n}(\%)$} \\
\hline Phải $(n=4)$ & $2(50)$ & $1(25)$ & $1(25)$ & \\
\hline Trái $(n=6)$ & $5(83,3)$ & $1(16,7)$ & $0(0)$ & \multirow{2}{*}{0,295} \\
\hline Hai bên $(n=6)$ & $2(33,33)$ & $1(16,67)$ & $3(50)$ & \\
\hline Tất cả & $9(56,25)$ & $3(18,75)$ & $4(25)$ & \\
\hline
\end{tabular}

\section{BÀN LUẬN}

Trong nghiên cứu của chúng tôi, để đánh giá đồng đều theo giới, chúng tôi đã chọn ngẫu nhiên 30 bệnh nhân nam và 30 bệnh nhân nữ, với độ tuổi trung bình là 45 , hơi cao hơn song không có sự khác biệt so với nhóm bệnh nhân của Abuzayed [2]. Tương tự với nghiên cứu của Abuzayed, nhóm bệnh nhân của chúng tôi đều là người trưởng thành (18-79 tuổi). Mikamia và cộng sự công bố số liệu gồm 300 bệnh nhân (tuổi từ 21-79), có độ tuổi trung bình là 58,6 [1], tuy nhiên tất cả các bệnh nhân trong nghiên cứu đều có chẩn đoán bệnh (mạch máu não hoặc u não), mặc dù tác giả đã loại trừ các tổn thương liên quan đến mỏm yên. Nghiên cứu của da Silva dựa trên 579 phim chụp cắt lớp vi tính đa dãy với độ tuổi thấp hơn nhóm bệnh nhân nghiên cứu của chúng tôi (38 tuổi), song có cả trẻ em (tuổi từ 0,2-90), sẽ phức tạp hơn về mức độ đánh giá do mỏm yên trước còn có thể thay đổi kích thước cùng với sự lớn lên của cơ thể trẻ. Theo da Silva, chiều rộng và chiều dài của mỏm yên tương ứng là $7,7 \pm 1,73(\mathrm{~mm})$ và $10,3 \pm 2,1$ (mm), tuy nhiên vì lý do ở trên, chúng tôi chỉ liệt kê ở đây mang tính tham khảo. Berger và cộng sự [3] nghiên cứu riêng về mỏm yên trước ở xác bào thai (từ 16 đến 28 tuần tuối), đo đạc trực tiếp trên xương sọ cho kết quả về kích thước của mỏm yên trước trên bào thai. Tuy nhiên, hạn chế của nghiên cứu của Berger là không đánh

giá được nguy cơ có hay không bệnh lý liên quan đến tốc độ phát triển của mỏm yên trước bình thường. Tuy nhiên, nghiên cứu của Berger cũng có giá trị trong việc xác định kích thước và biến đổi giải phẫu của mỏm yên trước ở bào thai cũng như ở bệnh nhi, giúp phẫu thuật viên han chễ được những tai biến liên quan đến phẫu thuật ở nhóm bệnh nhân này [3].

Khoảng cách giữa hai mỏm yên được Dagtekin và cộng sự đo đạc trên xương sọ [4], mặc dù không nói về độ tuổi, song cho kết quả tương tự (trung bình là 24,1mm; dao động từ 19-29,3mm).

Trong nghiên cứu của chúng tôi, khi so sánh kích thước của mỏm yên trước,cả chiều dài và chiều rộng đều không có sự khác biệt có ý nghĩa thống kê giữa hai giới nam và nữ. Hầu hết các tác giả không phân biệt giữa nam và nữ trong khi đo kích thước của mỏm yên trước, tuy nhiên chúng tôi cho rằng, yếu tố này cũng là một trong những biến số cần phân tích sâu thêm. Chúng tôi hy vọng sẽ có những nghiên cứu sâu hơn để đánh giá về liên quan này.

Đo đạc trên xương sọ, Dagtekin và cộng sự đã liệt kê kích thước bên phải và bên trái của mỏm yên trước (với $n=25$ ), kích thước này nhỏ hơn so với kích thước mà chúng tôi đo đạc (bảng 3). Chúng tôi lý giải về sự khác biêtt này là do chúng tôi sử dụng hình ảnh của phim chụp cắt lớp vi tính, so với đo đạc trên xương sọ của các tác giả này. Chúng tôi cho rằng, đo trên phim chụp cắt lớp vi tính sẽ có khả năng áp dụng thực tế hơn là so với đo trên xương sọ, bởi lẽ với phim chụp cắt lớp vi tính, chúng tôi đo được khoảng cách từ nền của mỏm yên đến đỉnh của mỏm yên, so với việc xác định vị trí chính xác của nền mỏm yên trên xương sọ rất khó khăn. Điểm thú vị là khi so sánh chiều dài và chiều rộng của mỏm yên ở từng giới, chúng tôi đã thây có sự khác biệt về chiều dày của mỏm yên trước 
hai bên ở nữ ( $p=0,004)$. Bởi số lượng bệnh nhân của chúng tôi chưa nhiêu, chúng tôi cho rằng khi có số lượng bệnh nhân lớn hơn sẽ có thêm nhiều điểm thú vị từ những kích thước này.

Chiều rộng của mỏm yên trước trong nghiên cứu của chúng tôi, ở cả bên phải và trái đều lớn hơn so với công bố của Dagtekin [4] (bảng 3). Điều này có thể lý giải bằng một số lý do sau: (1) phụ thuộc vào định nghĩa nền mỏm yên trước của mỗi tác giả là khác nhau và (2) phương pháp của chúng tôi sẽ xác định mỏm yên trước gián tiếp dựa vào phim cắt lớp, song lại đo đạc chính xác hớn, dựa trên máy tính. Tìm hiểu sâu hơn, chúng tôi thẩy chiều dài của mỏm yên trước bên phải trong nghiên cứu của chúng tôi thấp hơn so với bên trái ở cả hai giới, trong khi đó chiều dài của mỏm yên trước ở bên phải lớn hơn bên trái theo công bố của Dagtekin [4]. Sư khác biêt về kích thước giữa nghiên cứu của chúng tôi và Dagtekin là khá lớn $(2 \mathrm{~mm})$, và điêuu này cần thêm số lượng bệnh nhân để đưa ra kết luận, mặc dù số lượng xương sọ đo đạc của Dagtekin không lớn $(n=25)$.

Chi tiết hơn, da Costa và cộng sự đã đo đạc thể tích của mỏm yên trước, dựa trên phim chụp

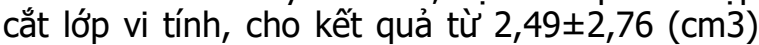
đến $7,08 \pm 3,45(\mathrm{~cm} 3)$, và có sự khác biệt rõ rệt theo lứa tuổi. Điều này khẳng định thêm rằng có sự thay đổi về thể tích (biến số gián tiếp của kích thước của mỏm yên trước) theo tuổi, và tác giả này cũng đã liệt kê chi tiết sự thay đổi này theo từng lứa tuổi, tuy không mồ tả chi tiết về kích thước.

Sự khác biêt về kích thước (chiều dài và chiều rộng) của mỏm yên trước giữa các tác giả, nếu loại trừ các yếu tố sai số đo đạc, là do hai yếu tố chính. Thứ nhất là định nghĩa của các mốc giải phẫu đo đạc, định nghĩa về mốc giải phẫu của nền mỏm yên, đỉnh mỏm yên và cách đo khoảng cách từ đỉnh xuống nền mỏm yên ở trên phim cắt lớp vi tính và trên xương sọ. Chúng tôi cho rằng, cách thức đo trên xương sọ sẽ có nhiều sai số hơn so với trên phim chụp cắt lớp vi tính, bởi hầu hết các nghiên cứu về giải phâuu mỏm yên trước đều đo đạc trên xương sọ, khiến cho khoảng cách từ mỏm yên đến nền của mỏm là đo trên xương, trong khi đó chiều dài này trên phim cắt lớp lại là đo bằng một đường thẳng vuông góc từ đỉnh mỏm yên xuống trọng tâm của nền mỏm yên.

Mức độ khí hóa của mỏm yên trước là một biến số khá khách quan, bởi hầu hết chỉ được xác định trên phim chụp cắt lớp vi tính. Có một số phương pháp phân loại mức độ khí hóa của cấu trúc giải phẫu này $[1,2,5]$, trong nghiên cứu này chúng tôi sử dụng phân loại của Abuzayed.

Không có khí hóa của mỏm yên trước gặp ở $73,33 \%(66,7 \%$ ở nam và $80 \%$ ở nữ). Khí hóa mỏm yên với các mức độ khác nhau gặp ở $26,67 \%$, cao hơn rất nhiều so với công bố của Abuzayed (9,6\%) [2], hay Mikami (9,2\%) [1], song tương tự với báo cáo của da Costa $(25,5 \%)$ [5]. Khi tính theo bên, tỉ lệ mỏm yên trước có khí hóa bên phải là $6,7 \%$ trong nghiên cứu của chúng tôi, thấp hơn so với của da Costa (20\%), song tương tự với công bố của Mikami (28 trong số 300 phim chụp cắt lớp vi tính, chiếm9,3\%) [1]. Kết quả tương tự với ở bên phải. Cả hai tác giả Mikami [1] và da Costa [5] đều không đề cập đến phân bố về giới.

Phân bố mức độ khí hóa theo từng bên hoặc cả hai bên, kết quả ở bảng 5 trong nghiên cứu của chúng tôi đã không thấy có sự khác biệt có ý nghĩa thống kê $(p<0,05)$. Nghiên cứu của chúng tôi cho kết quả tương tự với của Mikami về phân bố theo từng loại (type) khí hóa mỏm yên trước, trong đó loại I có tần xuất gặp nhiều nhất [1]. Kết quả tương tự về xu hướng phân bố cũng gặp trong nghiên cứu của da Costa[5] hay Abuzayed (38\% type I) [2]. Da Costa còn phân tích sâu hơn, theo từng lứa tuổi thập niên về phân bố khí hóa của mỏm yên trước, từng bên. Từ đó tác giả này cho biết quá trình khí hóa mỏm yên chưa bắt đầu ở dưới 10 tuổi. Phát hiện này cần phải được ghi nhận đối với bệnh nhi, đặc biệt là khi phẫu thuật u sọ hầu (một dạng bệnh rất thường gặp ở trẻ em) hiện nay đang được áp dụng bằng đường mổ nội soi qua xoang bướm ngày càng phổ biến [6].

\section{KẾT LUÂN}

Qua nghiên cứu giải phẫu mỏm yên trước trên phim chụp cắt lớp vi tính đa dãy ở 60 bệnh nhân trưởng thành, chúng tôi rút ra một số kết luận sau. Kích thước chiều rộng của mỏm yên trước Chiêu rộng mỏm yên trước 10,57 \pm $1,66 \mathrm{~mm}$, chiều dài mỏm yên trước $9,57 \pm 1,90$ $(\mathrm{mm})$. Chiều dài mỏm yên trước bên trái dài hơn bên phải ở nữ. Có $26,67 \%$ số bệnh nhân có khí hóa mỏm yên trước trong đó loại I chiếm tỉ lệ cao nhất.

\section{TÀI LIẸU THAM KHẢO}

1. Mikami, T., et al., Anatomical variations in pneumatization of the anterior clinoid process. J Neurosurg, 2007. 106(1): p. 170-4.

2. Abuzayed, B., et al., Pneumatization degree of the anterior clinoid process: a new classification. Neurosurg Rev, 2010. 33(3): p. 367-73; discussion 374. 
3. Beger, O., et al., Anatomy of the Anterior Clinoid Process in Human Fetuses. J Craniofac Surg, 2020. 31(5): p. 1469-1473

4. Dagtekin, A., et al., Microsurgical anatomy and variations of the anterior clinoid process. Turk Neurosurg, 2014. 24(4): p. 484-93.

5. da Costa, M.D.S., et al., Anatomical Variations of the Anterior Clinoid Process: A Study of 597 Skull
Base Computerized Tomography Scans. Oper Neurosurg (Hagerstown), 2016. 12(3): p. 289297.

6. Evans, J.J. and T.J. Kenning, Craniopharyngiomas: Comprehensive Diagnosis, Treatment and Outcome. 2014: Elsevier Science.

\title{
CÁC YẾU TỐ ẢNH HƯỞNG ĐẾN KẾT QUẢ ĐIỀU TRI LASER TẠO HÌNH VÙNG BÈ CHỌN LOQC TRÊN BÊ̂NH NHÂN GLÔCÔM GÓC MỞ ĐÃ ĐƯợC ĐIỀU TRI THUỐC TRA HẠ NHÃN ÁP
}

\author{
Đỗ Tấn ${ }^{1}$, Phạm Thị Thu Thủy², Nguyễn Đức Thịnh²
}

TÓM TẮT

Mục tiêu: Nhận xét một số yếu tố liên quan đến kết quả điều trị tạo hình vừng bè chọn lọc bằng laser trên bệnh nhân glôcôm góc mở đã được điêuu trị thuốc tra hạ nhãn áp. Đối tượng phương pháp nghiên cứu: nghiên cứu mô tả trên 40 mắt của 28 bênh nhân glôcôm góc mở nguyên phát và thứ phát do thuốc đã tra thuốc ha nhãn áp, được tao hình vùng bè chọn loc bằng laser $360^{\circ}$. Tình trạng thị lực, thị trường, nhã̉n áp, góc tiền phòng, đáy mắt, thông số laser, số thuốc tra được đánh giá tại các thới điểm trước và sau điều trị 2 tuần, 1 tháng, 3 tháng. Kết quả: Có mối liên quan giữa giới tính, tình trạng sắc tố vùng bè, nhãn áp trước điểu trị và thành cồng điều tri. Tai thới điểm 2 tuần bệnh nhân nam có tỷ lệ thành công cao hơn bênh nhân nữ $(p=0,013)$. Tai thời điểm 3 tháng sắc tố vùng bè càng cao càng làm tăng mức độ thành công điêu trị $(p=0,017)$. Tại thời điểm 1 tháng nhãn áp trước điều trị càng cao càng làm tăng mức đô thành công điều trị $(p=0,013)$. Không tìm thấy mối liên quan có ý nghĩa thống kê giữa tuổi, thời gian mắc bênh, số thuốc tra hạ nhãn áp trước điếu trị, giai đoạn bểnh, năng lượng laser đến thành công của điêuu trị. Kết luận: Có mối liên quan có ý nghĩa giữa giới tính, sắc tố vùng bè, nhãn áp trước điều trị với tỷ lệ thành công của điêu trị

Tư khóa: Glốcôm góc mở, laser tạo hình vùng bè, thuốc hạ nhãn áp

\section{SUMMARY}

\section{IMPACTING FACTORS FOR OUTCOME OF} SLT ON MEDICALLY TREATED OAGs

Objective: To evaluate some impacting factor for SLT effectiveness on POAG eyes which was already treated with IOP lowering medications. Patients and Methods: Descriptive study on 40 eyes of 28 POAG and steroid-induced patients on IOP lowering

${ }^{1}$ Bệnh Viện Mắt Trung Ương

${ }^{2}$ Đai Hoc Y Hà Nôi

Chịu trách nhiệm chính: Đỗ Tấn

Email: dotan20042005@yahoo.com

Ngày nhận bài: 13.01.2021

Ngày phản biên khoa hoc: 11.3.2021

Ngày duyệt bài: 22.3.2021 medications who have been treated with $360^{\circ} \mathrm{SLT}$. VA, VF, IOP, gonioscopy, optic disc, Laser settings, number of IOP lowering medications were evaluated before treatment and after treatment at 2 weeks, 1 month, 3 months. Results: There were some relating factors for SLT outcome such as gender, trabecular pigment, pre-laser IOP. At 2 weeks after laser, success rate in male group was higher that female group $(p=0.013)$. At 3 months, higher pigmented group had higher success rate $(p=0.017)$. Similarly, at 1 month, higher pre-SLT IOP group got higher success rate $(p=0.013)$. There was no significant relation between age, duration of disease, number of IOP lowering medications, disease stage and treatment outcome. Conclusion: the significant impacting factors for SLT outcome on OAG eyes under medications were gender, pr-laser IOP and trabecular pigment.

Key words: POAG, SLT, IOP lowering medications

\section{I. ĐĂT VẤN ĐỀ}

Glôcôm là một trong những nguyên nhân hàng đầu gây mù lòa ở Việt Nam cũng như trên toàn thế giới. Bệnh gây tổn thương thần kinh thi giác không hồi phục và có thể dẫn đến mất thi lực hoàn toàn. Glốcôm góc mở nguyên phát là một tình trạng bệnh lý của thị thần kinh, tiến triển mạn tính, có sự kết hợp của nhiều yếu tố, đặc trưng bởi sự chểt của các tế bào hạch võng mạc, biểu hiện bằng tổn hại thị trường, lớp sợi thần kinh võng mạc và lõm teo đĩa thị giác. Lựa chọn hàng đầu trong điều trị glôcôm góc mở hiền nay vẫn là sử dung thuốc tra ha nhãn áp. Tuy nhiên, việc điều trị bằng thuốc có nhiều nhược điểm là giá thành cao, có thể gặp những tác dung phu của thuốc, đồng thời đòi hỏi người bênh phải tuân thủ điều trị thuốc mới đat hiêu quả duy trì nhãn áp ổn định. Phương pháp tạo hình vùng bè chọn lọc bằng laser được Latina và Park thực hiên lần đâuu vào năm 1995 đã cho thấy những ưu điểm nổi trội. Nhờ chỉ tác động chọn lọc lên các tế bào sắc tố mà không làm tổn thương các cấu trúc khác nên hạn chế tối đa các 